\title{
Effects of milk replacer acidification and free-access feeding on early life feeding, oral, and lying behavior of dairy calves
}

\author{
C. G. Todd, ${ }^{*}$ S. T. Millman,†‡ K. E. Leslie, ${ }^{*}$ N. G. Anderson,§ J. M. Sargeant, ${ }^{*}$ and T. J. DeVries ${ }^{1}$ \\ *Department of Population Medicine, Ontario Veterinary College, University of Guelph, Guelph, Ontario, Canada, N1G 2W1 \\ †Veterinary Diagnostic and Production Animal Medicine, lowa State University, Ames 50011 \\ ‡Biomedical Sciences, lowa State University, Ames 50011 \\ §Ontario Ministry of Agriculture, Food and Rural Affairs, Veterinary Science and Policy Unit, Elora, Ontario, Canada, NOB 1S0 \\ \#Centre for Public Health and Zoonoses, University of Guelph, Guelph, Ontario, Canada, N1G 2W1 \\ IIDepartment of Animal Biosciences, University of Guelph, Guelph, Ontario, Canada, N1G 2W1
}

\begin{abstract}
Acidification is a practical way of preserving the bacteriological quality of milk so that it can be fed to calves under free-access conditions. The objectives of this study were to evaluate how milk replacer acidification and free-access feeding affect dairy calf behavior during the first week of life. Sixteen Holstein male calves were purchased at birth and transported to the University of Guelph Kemptville Campus Dairy Education and Research Centre. Calves were randomly assigned to 1 of 4 milk feeding programs: (1) free-access (ad libitum) feeding of acidified milk replacer $(22 \%$ crude protein and $17 \%$ fat, $150 \mathrm{~g} / \mathrm{L} ; \mathrm{FA}) ;(2)$ restricted $(6 \mathrm{~L} / \mathrm{d}, 150$ $\mathrm{g} / \mathrm{L}$ ) feeding of acidified milk replacer (RA); (3) freeaccess feeding of nonacidified milk replacer (FN); and (4) restricted feeding of nonacidified milk replacer (RN). Formic acid was used to acidify milk replacer to a target $\mathrm{pH}$ between 4.0 and 4.5 . Video recordings of each calf at 1,2, and $6 \mathrm{~d}$ were analyzed continuously over $24 \mathrm{~h}$ for all occurrences of each behavior in the ethogram. Feeding behavior observations were organized into sucking bouts, from which feeding behavior outcome variables were calculated. Calves consuming acidified milk replacer demonstrated more fragmented feeding patterns, characterized by more pauses within a sucking bout (FA, FN, RA, and RN calves $=12.4$, 4.4, 13.7, and 11.9 pauses/bout, respectively) and longer sucking bout duration (FA, FN, RA, and RN calves $=8.8,5.2,9.3$, and $8.1 \mathrm{~min} /$ bout, respectively), than calves fed nonacidified milk replacer. Restricted-fed calves tended to have longer sucking bouts and performed more within-bout sucks (FA, FN, RA, and RN calves $=10.7,5.8,13.5$, and 14.1, respectively) and pauses than free-access calves. Acidification and free-
\end{abstract}

Received January 23, 2018.

Accepted May 13, 2018.

${ }^{1}$ Corresponding author: tdevries@uoguelph.ca access feeding did not affect lying duration. Calves assigned to the acidified feeding treatments tended to perform more grooming behavior than those fed nonacidified milk replacer (FA, FN, RA, and RN calves $=0.9,0.5,0.8$, and $0.6 \mathrm{~h} / \mathrm{d}$, respectively). Free-access feeding did not affect grooming duration. The observed differences in feeding and grooming behavior suggest that acidification to a $\mathrm{pH}$ between 4.0 and 4.5 may have altered the palatability of milk replacer. Calves assigned to the acidified milk replacer feeding treatments did not, however, show avoidance toward this feedstuff during the first week of life.

Key words: acidification, free-access feeding, behavior, calf

\section{INTRODUCTION}

Early life nutrition programs have traditionally restricted dairy calf daily intake of milk or milk replacer to approximately $10 \%$ of birth $\mathrm{BW}$, with the aim of encouraging greater solid feed consumption during the first weeks of life, promoting rumen development, and facilitating early weaning off milk (Drackley, 2008; Khan et al., 2011). However, there is growing interest in enhanced feeding strategies that allow calves to consume greater amounts of milk (Hammell et al., 1988; Jasper and Weary, 2002; Borderas et al., 2009a). Enhanced milk feeding supports greater nutrient intake and increased growth performance over traditional feeding methods (Diaz et al., 2001; Khan et al., 2007a,b; Borderas et al., 2009a), and is associated with improved milk production later in life (Soberon et al., 2012; Soberon and Van Amburgh, 2013; Gelsinger et al., 2016). Another advantage of enhanced milk feeding is the reduction in behavioral signs of hunger, including fewer unrewarded visits and competitive interactions at the feeding station, less nonnutritive sucking after milk ingestion and more time spent lying compared with traditional feeding practices (Jensen and Holm, 2003; De Paula Vieira et al., 2008; Borderas et al., 2009a; 
Rosenberger et al., 2017). Moreover, enhanced milk feeding promotes a more natural type of feeding behavior, wherein each calf has greater control over its milk intake, feeding duration, and meal patterns than calves reared under traditional feeding conditions (Appleby et al., 2001; Jensen, 2009; Miller-Cushon et al., 2013).

Ad libitum milk feeding for calves can be achieved by using automated feeders and free-access feeding systems. Automated feeders can be programmed to provide freshly mixed milk replacer each time a calf enters the feeding station. One of the main challenges with free-access feeding systems is that milk kept at ambient temperatures can support rapid microbial growth (Stewart et al., 2005; Cummins et al., 2016). High levels of bacterial contamination are associated with greater risk of calf morbidity and mortality, and reduced growth performance (Jamaluddin et al., 1996a,b; Armengol and Fraile, 2016). Acidification is a preservation method that can be used to inhibit microbial growth in animal feedstuffs (Argagón, 2007). Acidifying milk, milk replacer, or colostrum to a target $\mathrm{pH}$ between 4.0 and 4.5 has been shown to effectively preserve the bacteriological quality of milk so that it can be safely fed to calves under free-access conditions (Collings et al., 2011; Parker et al., 2016; Todd et al., 2016).

Effects of milk replacer acidification on calf behavior are largely unknown. Cattle can discriminate between acidic solutions and water at $\mathrm{pH} 4.8$, and exhibit rejection responses at $\mathrm{pH}$ levels below 3.6 (Goatcher and Church, 1970). Acidification with formic acid to a target $\mathrm{pH}$ between 4.0 and 4.5 has been shown to limit voluntary intake of milk replacer by approximately 1 L/d (Todd et al., 2016). Moreover, some calves reject colostrum or milk replacer acidified to $\mathrm{pH}$ less than 4.5 (Collings et al., 2011; Hill et al., 2013). Collectively, these findings suggest that acidification may alter the palatability of milk fed to calves. There is also evidence that calves fed acidified milk replacer ad libitum have lower abomasal and fecal $\mathrm{pH}$ than calves fed restricted amounts of nonacidified milk replacer (Woodford et al., 1987). Diets that promote lower gastric $\mathrm{pH}$ tend to be associated with inflammation and ulceration of the stomach mucosal epithelium in horses (Nicol et al., 2002), as well as the performance of unwanted oral behaviors, such as wood chewing, coprophagia, and crib-biting (Willard et al., 1977; Nicol et al., 2002). Thus, ingestion of acidified milk replacer may influence digestive function, gastrointestinal discomfort, and nonnutritive oral behavior.

The objectives of this study were to evaluate how milk replacer acidification (acidified versus nonacidified) and feeding level (free access versus restricted) affect the feeding, oral, and lying behavior of calves during the first week of life. The hypothesis underlying this study was that acidification would negatively affect the palatability of milk replacer and increase gastric acidity, which would result in calves having more interrupted sucking behavior, altered feeding patterns, greater nonnutritive oral behavior, and greater lying duration. We also hypothesized that free-access feeding would better satisfy hunger and promote more natural feeding patterns, resulting in greater lying duration than restricted feeding.

\section{MATERIALS AND METHODS}

\section{Animals, Housing, and Management}

Sixteen male Holstein calves were purchased at birth from 2 commercial dairy farms in eastern Ontario, Canada. Calves were transported within $24 \mathrm{~h}$ of birth (0 d of age) from the source farm to the University of Guelph Kemptville Campus Dairy Education and Research Centre (Kemptville, ON, Canada). Calves were housed in individual pens $(1.22 \mathrm{~m}$ wide and 1.83 $\mathrm{m}$ long; Figure 1) on a straw and shavings pack. Due to solid pen partitions, visual contact between calves was only possible when calves had their heads out of the front of the pen (by the feed and water buckets), but they were within auditory range of one another. Individual housing was used to facilitate the collection of individual feed intake data. Management conditions were representative of commercial dairy operations in Ontario, and in accordance with guidelines of the Canadian Council on Animal Care (CCAC, 2009). All study procedures were reviewed and approved by the University of Guelph Animal Care Committee (\# 07R109).

\section{Experimental Design and Feeding Treatments}

A $2 \times 2$ factorial design was used to test the following milk feeding programs: free-access (ad libitum) feeding of acidified milk replacer (FA), free-access feeding of nonacidified milk replacer $(\mathbf{F N})$, restricted (6 L/d) feeding of acidified milk replacer (RA), and restricted feeding of nonacidified milk replacer $(\mathbf{R N})$. This experimental design allowed for the independent effects of acidification and feeding level, as well as the interaction between these factors, to be tested. Calves were blocked by source farm and randomly allocated to feeding treatment as they arrived at the research facility. The randomization sequence was determined using a random number generator software program. Calves did not differ by treatment group for birth weight (mean \pm SD: $\mathrm{FA}=50.0 \pm 3.8 \mathrm{~kg}, \mathrm{FN}=46.0$ $\pm 4.2 \mathrm{~kg}, \mathrm{RA}=48.0 \pm 6.5 \mathrm{~kg}, \mathrm{RN}=47.3 \pm 8.0 \mathrm{~kg} ; P$ 
$=0.59)$ or serum total protein concentration (mean \pm $\mathrm{SD}: \mathrm{FA}=5.3 \pm 0.5 \mathrm{~g} / \mathrm{dL}, \mathrm{FN}=5.1 \pm 0.9 \mathrm{~g} / \mathrm{dL}, \mathrm{RA}$ $=5.3 \pm 0.4 \mathrm{~g} / \mathrm{dL}, \mathrm{RN}=5.8 \pm 0.9 \mathrm{~g} / \mathrm{dL} ; P=0.44$ ). Research technicians who were responsible for the feeding management and care of the calves were not blind to treatment assignment.

Calves were fed a nonmedicated commercial milk replacer (Grober High Performance Calf Milk Replacer, Cambridge, ON, Canada) that contained $22 \% \mathrm{CP}$ and $17 \%$ fat. A mixing ratio of $150 \mathrm{~g} / \mathrm{L}$ was used for preparing milk replacer. Calves assigned to the $\mathrm{FN}$ and $\mathrm{RN}$ treatments were fed milk replacer freshly prepared at each feeding. Calves assigned to the FA and RA treatments were fed milk replacer that had been acidified with diluted formic acid (The Acidified Milk Solution, 9.8\% formic acid, NOD Apiary Products Ltd., Frank- ford, ON, Canada) to a target pH between 4.0 and 4.5 . The $\mathrm{pH}$ of the acidified milk replacer was checked at least twice daily using a waterproof combination tester (HI 98129 Combo pH, EC/TDS and temperature tester, Hanna Instruments, Laval, QC, Canada). To allow for contact time between the acid and potential bacterial contamination of the milk replacer, acidified milk replacer was prepared at least $8 \mathrm{~h}$ before being fed to the FA and RA calves.

Milk replacer was offered to the calves by a teat and bucket feeding system. A nutritive artificial teat (Peach Teat, Skellerup Industries, Christchurch, New Zealand) was fastened to the rear wall of each pen at a height of $0.80 \mathrm{~m}$, and each calf had continuous access to its teat. The nutritive teat was attached to a plastic tube fitted with a weighted one-way valve. The plastic tube

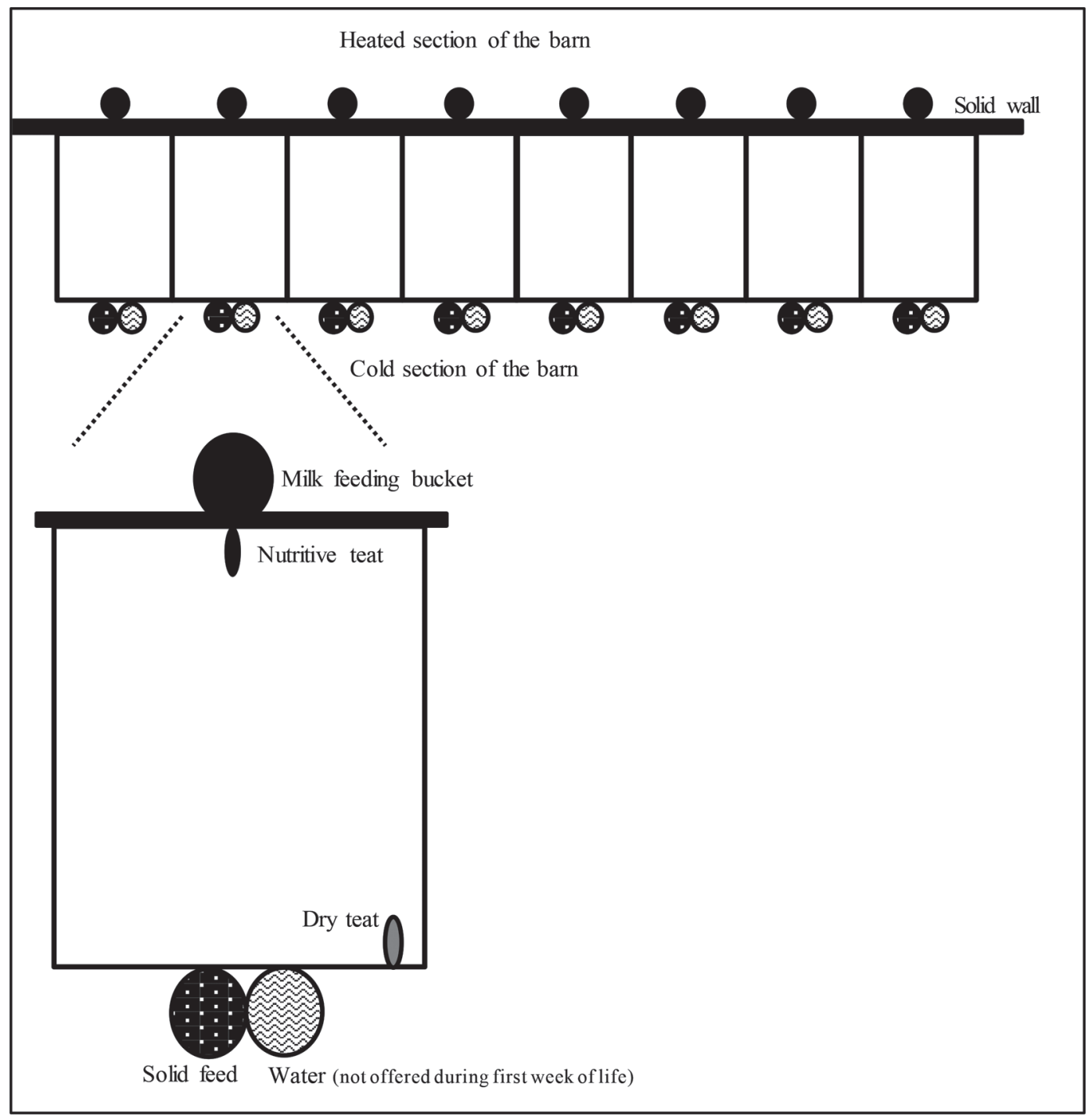

Figure 1. Schematic of the barn layout and each individual calf pen. 
connected the teat to a 20-L polyethylene bucket with a lid. To prevent the milk replacer from freezing in winter months, the feeding buckets were kept at ambient temperature within a heated section of the barn, which was located directly behind the rear wall of the calf pens. All feeding equipment (teats, plastic tubes, buckets) was washed daily. Each calf also had continuous access to a dry (nonnutritive) teat (modified Replacement Teat, Nasco Farm and Ranch, Newmarket, ON, Canada) that was fastened to the front gate of the pen at a height of $0.90 \mathrm{~m}$.

The FA and FN calves were offered ad libitum acidified and nonacidified milk replacer, respectively. The $\mathrm{RA}$ and RN calves were offered $3 \mathrm{~L}$ of acidified and nonacidified milk replacer, respectively, at the morning $(0800 \mathrm{~h})$ and afternoon feedings $(1600 \mathrm{~h})$. At each feeding, milk replacer intake since the previous feeding was measured for each calf. Calves that did not voluntarily consume milk replacer between feedings were offered $2 \mathrm{~L}$ of milk replacer by nurse bottle; calves were not force-fed milk replacer at any time. Milk replacer intake was determined daily throughout the pre-weaning period. Ad libitum starter feed (Purina Fastart Calf Startena*Ex Dec Multi-Particle, Calf Starter Complete, $18 \%$ CP, $2 \%$ fat, $0.0050 \%$ decoquinate, Agribrands Purina, Canada Ltd., Woodstock, ON, Canada) was offered to the calves in individual buckets. Water was offered to the calves in individual buckets beginning at $7 \mathrm{~d}$. The starter feed and water buckets were attached to the front gate of each pen (Figure 1).

\section{Collection of Behavioral Data}

Behavior was recorded continuously during the first week of life using video recordings. Video cameras (Panasonic WV-CP244 Color CCTV Cameras, Heads WV-LZA61/2, Panasonic Canada Inc., Mississauga, ON, Canada) were mounted directly above each individual pen and positioned to provide an unobstructed overhead view of the focal calf and its pen surroundings (Figure 1). Video signals were fed into a multiplexer unit (Panasonic WJ-FS409, Panasonic Canada Inc.) and recorded in 24-h time mode at 20 frames/s using a time-lapse VHS recording system (Panasonic AG-RT650, Panasonic Canada Inc.). Natural and fluorescent lighting were used from 0700 to $1700 \mathrm{~h}$ and red lights were used to facilitate recording during the nighttime hours.

The analog video recordings were converted to digital format to enable data collection using the Observer 5.0 software (Noldus Information Technology, Wageningen, the Netherlands). Calves were observed individually for three 24-h time periods, beginning at $1300 \mathrm{~h}$, on 1,2 , and $6 \mathrm{~d}$ of age. Video recordings were analyzed continuously for all occurrences of behavior (Martin and Bateson, 1993). The ethogram used to collect behavioral data is presented in Table 1. Data collection was completed by 3 observers who were trained on the ethogram and blinded to treatment assignment.

\section{Feeding Behavior Analysis and Calculations}

Feeding behavior of the calves was organized into sucking bouts, consisting of periods of nutritive teatengaged behavior, butting events, and nonsucking pauses (Hammell et al., 1988; Appleby et al., 2001). Feeding behavior analysis was performed to differentiate between short pauses within a sucking bout and breaks separating different sucking bouts. A sucking bout criterion was calculated for each calf by modeling the frequency distribution of $\log _{10}$-transformed time intervals between nutritive teat-engaged visits across the $3 \mathrm{~d}$ of observation (DeVries et al., 2003; MillerCushon et al., 2013). These $\log _{10}$-transformed time intervals were described as having a bimodal normal distribution: one distribution for within-bout intervals and a second distribution for between-bout intervals. A mixture of 2 normal distributions was fit to these data using the MIX 3.1.3 software (Macdonald and Green, 1988), and the sucking bout criterion was determined as the time point where the distribution curve for the within-bout intervals intersected the distribution curve for the between-bout intervals (DeVries et al., 2003). Time intervals between nutritive teat-engaged visits that were less than the sucking bout criterion were defined as short within-bout pauses. Conversely, time intervals greater than the sucking bout criterion were classified as breaks separating 2 sucking bouts. This information was then used to calculate the feeding behavior outcome variables described in Table 2 .

\section{Statistical Analysis}

All statistical analyses were performed using SAS software version 9.2 (SAS Institute Inc., Cary, NC). The primary experimental unit in all analyses was the individual calf. Median daily intake of milk replacer was determined for each feeding treatment. A generalized linear model was used to test for differences by feeding treatment for sucking bout criterion (Dohoo et al., 2010). Repeated-measures analyses were used for all other behavioral outcome variables because calves were observed for a total of $3 \mathrm{~d}$. Generalized linear mixed models were constructed to examine the effects of acidification and feeding level on the duration of lying, active, grooming, pen oral manipulation, dry teat-directed, and solid feed-directed behavior (Dohoo et al., 2010). Generalized linear mixed models were also 
Table 1. Ethogram of behaviors performed by the calves

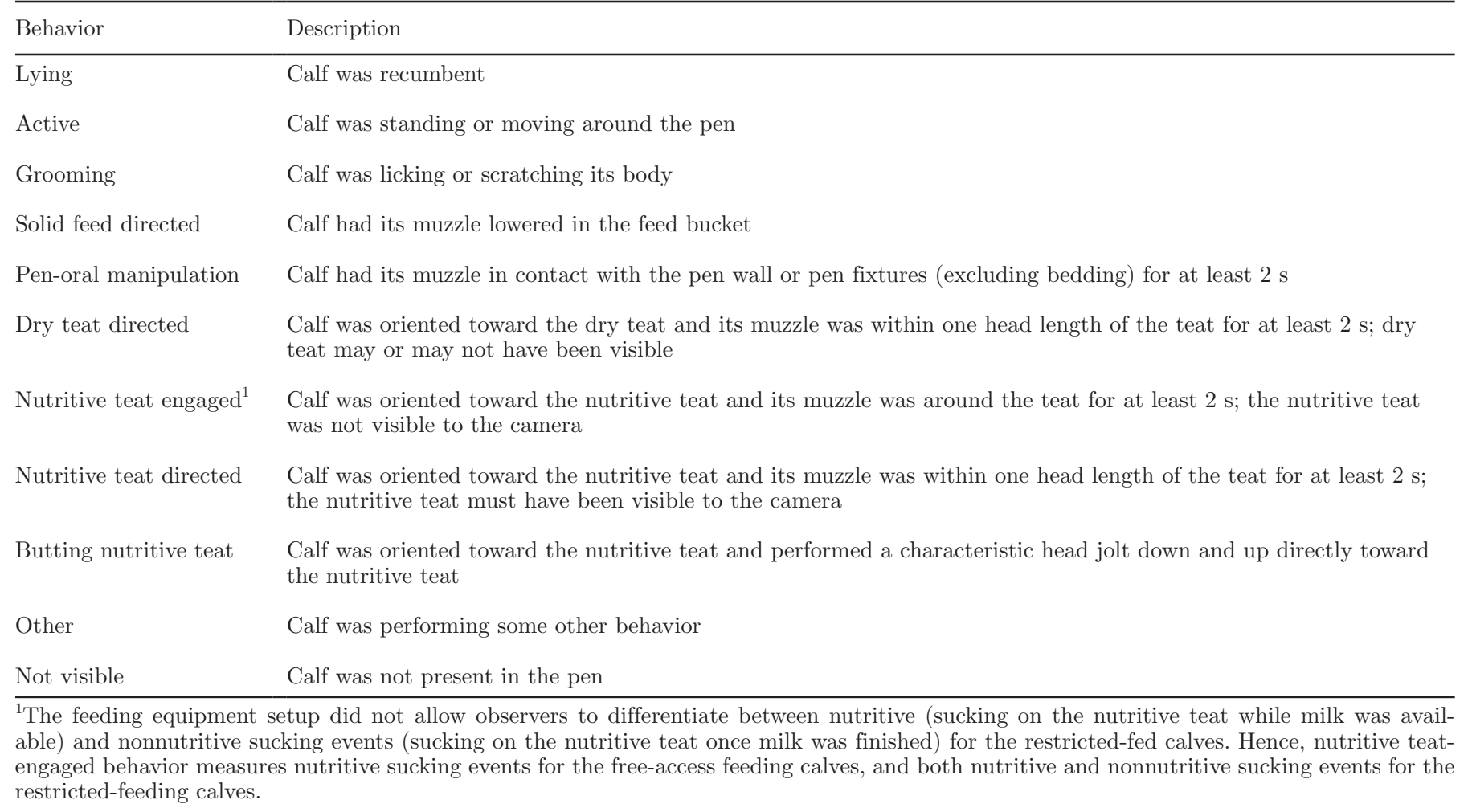

constructed to examine the effects of acidification and feeding level on the following feeding behavior outcome variables: total nutritive teat-engaged duration, total sucking bout duration, frequency of sucking bouts, mean sucking bout duration, frequency of within-bout sucks, mean duration of within-bouts sucks, frequency of within-bout pauses, mean duration of within-bout pauses, total nutritive teat-directed duration, and frequency of nutritive teat butting. All of these data were treated as continuous measurements. Each outcome

Table 2. Calculated outcome variables from the feeding behavior analysis

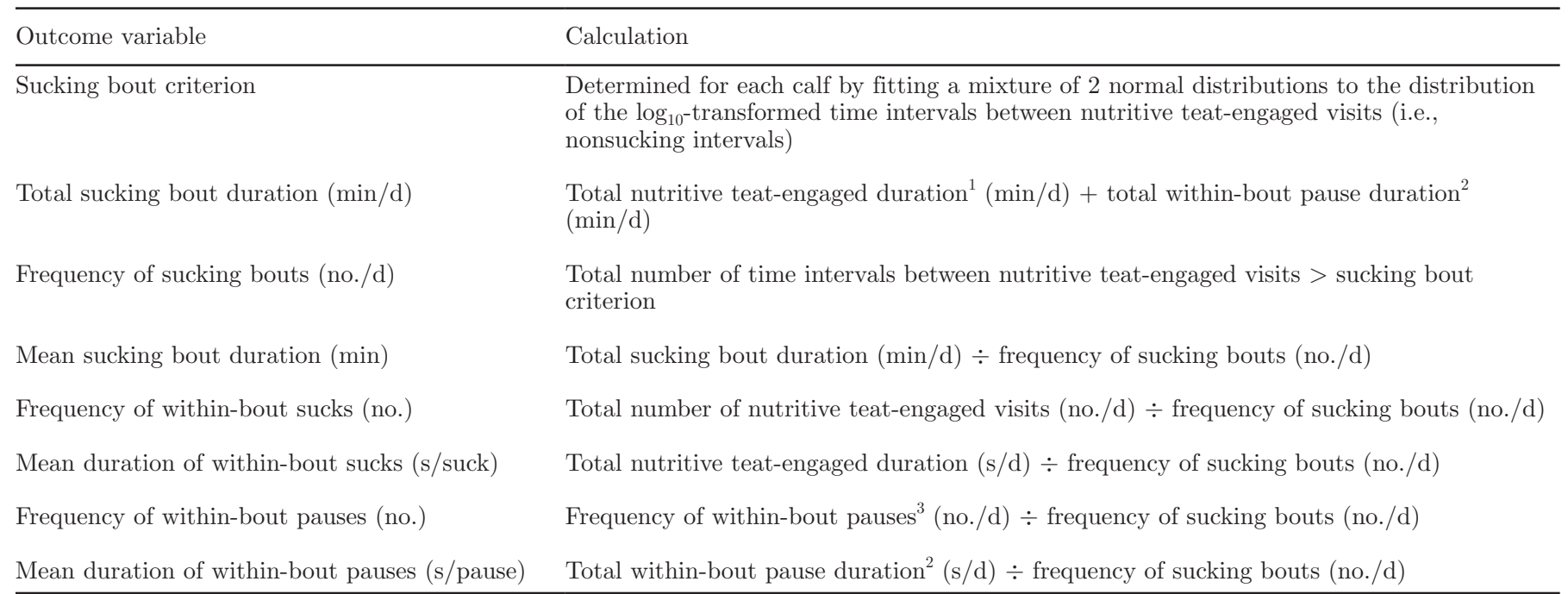

\footnotetext{
${ }^{1}$ Total nutritive teat-engaged duration $=$ sum of all nutritive teat-engaged behavior.

${ }^{2}$ Total within-bout pause duration $=$ sum of time intervals $<$ sucking bout criterion.

${ }^{3}$ Frequency of within-bout pauses $=$ total number of time intervals $<$ sucking bout criterion.
} 
variable, with the exception of frequency of nutritive teat butting, was modeled with a normal distribution and an identity link, and included a repeated-measures statement to account for within-calf correlation between observation days. Frequency of nutritive teat butting was modeled with a negative binomial distribution and a log link, and included a repeated-measures statement to account for within-calf correlation between observation days.

Milk replacer acidification and feeding level were included in each model as fixed independent variables, regardless of significance. Interaction between acidification and feeding level was tested in each model. Observation day was controlled for as a fixed categorical effect. All observations from any day where a calf was bottle-fed milk were excluded from the feeding behavior analyses. Significance and tendencies were declared at $P<0.05$ and $P<0.10$, respectively.

Each final model was evaluated for the assumptions of homoscedasticity and normality of residuals. Homoscedasticity was assessed by visually examining a scatterplot of the residuals against the predicted values. Normality was assessed using histogram and normal probability plots, as well as checking the residuals for skewness and kurtosis. To improve homoscedasticity and normalize the distribution of the residuals, square root transformations were applied to the following outcome variables: pen oral manipulation duration, dry teat-directed behavior, solid feed-directed behavior, total sucking bout duration, frequency of within-bout pauses, and total nutritive teat-directed duration. To improve homoscedasticity and normalize the distribution of the residuals, natural logarithm transformations were applied to the following outcome variables: frequency of within-bout sucks, mean duration of withinbout sucks, and mean duration of within-bout pauses. Back-transformed means and 95\% confidence intervals are presented for each transformed outcome variable.

The fit of each generalized linear mixed model was examined by identifying the correlation structure that resulted in the smallest Akaike information criterion. A first-order autoregressive correlation structure was specified for the following outcome variables: active duration, grooming duration, solid feed-directed behavior duration, total nutritive teat-engaged duration, total sucking bout duration, mean duration of within-bout sucks, mean duration of within-bout pauses, total nutritive teat-directed duration, and frequency of nutritive teat butting. A Toeplitz correlation structure was specified for the following outcome variables: lying duration, pen oral manipulation duration, dry teatdirected behavior duration, frequency of sucking bouts, mean sucking bout duration, frequency of within-bout sucks, and frequency of within-bout pauses.

\section{RESULTS}

Behavioral observations on $\mathrm{d} 1$ for one of the $\mathrm{FN}$ calves were treated as missing data in all analyses because of a video recording error. Four other calves (1 FN, 2 RA, and $1 \mathrm{RN}$ ) were fed milk replacer by nurse bottle on d 1; thus, the d-1 behavioral observations for these calves were excluded from all milk feeding behavior analyses.

Lying behavior and nonnutritive oral behavior of the calves are presented in Table 3. Calves spent more than two-thirds of their day lying in a recumbent position. Lying times were greater on d 1 than on d 6 (19.6 vs. $18.0 \mathrm{~h} / \mathrm{d} ; P=0.01$ ), but did not differ for the other observation days. Acidification and feeding level did not affect lying duration. Calves were less active on $\mathrm{d} 1$ than on $\mathrm{d} 2(2.3$ vs. $3.1 \mathrm{~h} / \mathrm{d} ; P=0.045)$ or d $6(2.3$ vs. $3.3 \mathrm{~h} / \mathrm{d} ; P=0.046)$. Duration of active behavior was not influenced by acidification or feeding level. Calves performed more grooming behavior on $\mathrm{d} 6$ than on $\mathrm{d}$ $1(1.1$ vs. $0.4 \mathrm{~h} / \mathrm{d} ; P<0.001)$ or $\mathrm{d} 2(1.1$ vs. $0.6 \mathrm{~h} / \mathrm{d}$; $P<0.01)$. Calves in the acidified groups tended to groom for longer than calves in the nonacidified groups $(0.9$ vs. $0.5 \mathrm{~h} / \mathrm{d} ; P=0.06)$. Grooming behavior was not affected by feeding level. Calves engaged in more pen oral manipulation on $\mathrm{d} 6$ than on $\mathrm{d} 2(11.0$ vs. 1.2 $\min / \mathrm{d} ; P<0.01)$, but not on $\mathrm{d} 1$ versus $\mathrm{d} 2$, or $\mathrm{d} 1$ versus d 6 . Dry teat-directed behavior did not differ by observation day $(P=0.62)$. Acidification and feeding level did not influence the amount of time calves spent exhibiting pen oral manipulation or dry teat-directed behavior. Calves had very little interest in solid feed during the first week of life, but spent more time performing solid feed-directed behavior on $\mathrm{d} 6$ than on d 1 (2.1 vs. $0.02 \mathrm{~min} / \mathrm{d} ; P<0.001)$ or $\mathrm{d} 2(2.1$ vs. $0.2 \mathrm{~min} / \mathrm{d} ; P<0.001)$. Acidification and feeding level were not associated with solid feed-directed behavior. No interactions between acidification and feeding level were detected for any outcome variables.

Median milk replacer intake for the $\mathrm{FA}$ and $\mathrm{FN}$ calves was 2.6 and $1.9 \mathrm{~L}$ on d $1,5.1$ and $3.6 \mathrm{~L}$ on d 2, and 7.7 and $7.5 \mathrm{~L}$ on $\mathrm{d} 6$, respectively. Median milk replacer intake for the RA and $\mathrm{RN}$ calves was 2.7 and $4.0 \mathrm{~L}$ on $\mathrm{d} 1,3.8$ and $5.1 \mathrm{~L}$ on $\mathrm{d} 2$, and 6.0 and $5.6 \mathrm{~L}$ on d 6 , respectively. In addition, median daily intake of milk replacer for the FA, FN, RA, and RN calves from 7 to $28 \mathrm{~d}$ of age was $10.6,12.5,6.0$, and $6.0 \mathrm{~L} / \mathrm{d}$, respectively.

Sucking bout criterion values for the calves ranged from 0.7 to 16.7 min (mean \pm SD: $6.4 \pm 5.4$ min). There was no difference by treatment group for sucking bout criterion $(P=0.33)$. Nutritive teat-engaged behavior did not differ by observation day $(P=0.12)$. Calves had more sucking bouts and longer total sucking bout 
Table 3. Effects of milk replacer acidification and feeding level on lying and nonnutritive oral behavior for 16 Holstein male calves over three 24-h time periods at 1,2 , and $6 \mathrm{~d}^{1}$ of life

\begin{tabular}{|c|c|c|c|c|c|c|c|}
\hline \multirow[b]{2}{*}{ Outcome variable } & \multicolumn{4}{|c|}{ Treatment group ${ }^{2}$} & \multicolumn{3}{|c|}{$P$-value ${ }^{3}$} \\
\hline & FA & FN & RA & $\mathrm{RN}$ & $\mathrm{a}$ & $\mathrm{b}$ & $a \times b$ \\
\hline Active $(\mathrm{h} / \mathrm{d})$ & $2.7(1.9,3.5)$ & $2.8(2.0,3.6)$ & $2.8(2.0,3.6)$ & $3.3(2.4,4.1)$ & 0.48 & 0.39 & 0.63 \\
\hline Grooming $(\mathrm{h} / \mathrm{d})$ & $0.9(0.6,1.2)$ & $0.5(0.1,0.8)$ & $0.8(0.5,1.1)$ & $0.6(0.3,1.0)$ & 0.06 & 0.83 & 0.42 \\
\hline Pen oral manipulation $(\mathrm{min} / \mathrm{d})$ & $5.3(1.4,11.6)$ & $4.4(0.9,10.5)$ & $5.3(1.2,12.1)$ & $5.3(1.1,12.5)$ & 0.84 & 0.88 & 0.86 \\
\hline Dry teat directed $(\min / \mathrm{d})$ & $1.3(0.1,3.9)$ & $1.4(0.1,4.1)$ & $0.8(0.1,3.3)$ & $1.5(0.1,4.1)$ & 0.72 & 0.81 & 0.74 \\
\hline
\end{tabular}

${ }^{1}$ Effect of day on the outcome variables are reported in text; $\mathrm{df}=2,29$ (d-1 observations for 1 calf were missing because of a video recording error).

${ }^{2}$ Least squares means and $95 \%$ CI for the following treatment groups: FA $=$ free-access feeding of acidified milk replacer; FN $=$ free-access feeding of nonacidified milk replacer; RA = restricted feeding of acidified milk replacer; $\mathrm{RN}=$ restricted feeding of nonacidified milk replacer.

${ }^{3} \mathrm{a}=$ effect of milk replacer acidification, $\mathrm{df}=1,12 ; \mathrm{b}=$ effect of milk replacer feeding level, $\mathrm{df}=1,12 ; \mathrm{a} \times \mathrm{b}=$ interaction of milk replacer acidification and feeding level, df $=1,12$.

duration on d 6 compared with d 1 (12.8 vs. 6.2 bouts/ day; $P<0.001$; and 74.0 vs. $34.2 \mathrm{~min} / \mathrm{d} ; P<0.001)$ and d 2 (12.8 vs. 8.8 bouts/day; $P=0.01$; and 74.0 vs. $67.1 \mathrm{~min} / \mathrm{d} ; P=0.01)$. Mean sucking bout duration was longer on $\mathrm{d} 2$ than on d 6 (8.8 vs. $6.5 \mathrm{~min} ; P=$ $0.03)$, but did not differ between d 1 and d 2 or between d 1 and d 6. Calves performed fewer sucks and pauses within sucking bouts on $\mathrm{d} 6$ than on $\mathrm{d} 2(7.0$ vs. 14.4 sucks; $P=0.001$; and 5.8 vs. 14.5 pauses; $P<0.001$ ). Calves also had longer within-bout sucking duration on d 6 than on $\mathrm{d} 2(18.9$ vs. $13.2 ; P=0.02)$. Frequency and duration of within-bout sucking and pausing on $\mathrm{d} 1$ did not differ from that on $\mathrm{d} 2$ or $\mathrm{d} 6$. Calves exhibited more nutritive teat-directed behavior on $\mathrm{d} 6$ than on $\mathrm{d}$ 1 (17.2 vs. $6.3 \mathrm{~min} / \mathrm{d} ; P<0.01)$ and d 2 (17.2 vs. 11.2 ; $P=0.02)$. In addition, calves performed more nutritive teat butting behavior on $\mathrm{d} 2$ than on $\mathrm{d} 1$ ( 8.0 vs. 2.2 butting events/day; $P=0.02$ ).

Feeding behavior involving the nutritive teat by treatment group is shown in Table 4. Calves assigned to the acidified groups had longer sucking bouts and paused more often within a sucking bout than calves in the nonacidified group. Acidification did not affect any of the other feeding behavior outcome variables. Sucking bouts for the restricted-fed calves were characterized as containing more individual sucking events and a greater number of pauses than that of the freeaccess calves. Restricted feeding tended to result in more nutritive teat-engaged behavior, longer sucking bouts, and greater total sucking bout duration than free-access feeding. There were no interactions between the effects of acidification and feeding level for any of the feeding behavior outcome variables. However, FN calves tended to have fewer within-bout pauses than FA, RA, and RN calves $(P=0.08)$. Moreover, the RN calves tended to perform more nutritive teat-directed behavior compared with the FA, FN, and RA calves $(P=0.07)$.

\section{DISCUSSION}

The most interesting results from this study relate to the effects of acidification and feeding level on calf feeding behavior. Acidification resulted in longer sucking bouts and more pauses within a given sucking bout. The greater number of pauses while sucking, which would have extended sucking bout duration, may have resulted because acidification altered the taste and reduced the palatability of the milk replacer. Calves may have perceived acidified milk replacer as being sour tasting (Hellekant et al., 2010). Conversely, nonacidified milk replacer would have had a sweeter taste, and calves are known to exhibit a preference for sweettasting substances (Hellekant et al., 1994). de Passillé and Rushen (2006b) have shown that the sweet taste of milk, specifically sugars such as lactose, stimulates sucking behavior in calves. Taste threshold tests have also documented that calves are sensitive to changes in acidity and will reject acidic solutions at $\mathrm{pH}$ levels below 3.6 (Goatcher and Church, 1970). Moreover, some calves have been shown to reject colostrum acidified with formic acid to $\mathrm{pH}$ between 4.3 and 4.4 (Collings et al., 2011), as well as milk replacer acidified with citric acid to $\mathrm{pH} 4.2$ (Hill et al., 2013). All calves were fed untreated (nonacidified) colostrum at their source farm, immediately after birth. Early sensory inputs, such as an animal's first feeding experience, can influence the development of dietary habits (Burghardt, 1967; Provenza and Balph, 1987; Villalba et al., 2012). Therefore, the ingestion of untreated colostrum may have reinforced a preference for sweet compounds. Further research is needed to test whether calves show a 
preference or aversion to acidified milk replacer, and to formally evaluate how the taste of the milk affects the feeding behavior of calves for both milk and solid food.

Acidification tended to influence grooming behavior but did not affect the performance of other oral activity. We initially hypothesized that in response to the taste of acidified milk replacer and the effects on gastric acidity, calves would redirect their oral behavior toward other targets, such as the dry teat or pen fixtures. Results of this study, however, demonstrated that calves assigned to the acidified feeding treatments did not differ in oral behavior directed at the environment, but rather showed similar nutritive teat-engaged and nutritive teat-directed behavior as calves in the nonacidified groups. This suggests that even if the acidified milk was perceived as unpalatable, calves were still sufficiently motivated to continue sucking the nutritive teat. Grooming duration varied widely within feeding treatment group but was similar to other reports on the grooming behavior of individually or group-housed preweaned calves (Veissier et al., 1997; Chua et al., 2002; Sutherland et al., 2017). The tendency for acidified-fed calves to express more grooming behavior may have been an adaptive response that helped to increase saliva output in an effort to buffer gastric acidity. The performance of wood chewing and crib-biting behavior has been proposed to serve a similar function in horses (Nicol et al., 2002). Moreover, to lend support to this hypothesis, dietary antacid supplementation has been shown to reduce crib-biting behavior in foals and mature horses (Mills and Macleod, 2002; Nicol et al., 2002). Development of wood chewing and crib-biting behavior in foals during the pre- and postweaning periods has been associated with more fragmented sucking patterns, including greater within-bout terminations or pauses (Nicol and Badnell-Waters, 2005). Hence, it is evident that based on that equine work, relationships between milk replacer acidification, sucking behavior, and the development of oral behavior in calves need to be further explored. The lack of differences in nonnutritive oral behavior between the calves fed acidified and nonacidified milk replacer may have been due to an age effect or low statistical power. Post-hoc power analyses estimated that, with the sample size in the current study, power was less than $25 \%$ to detect differences in grooming, pen oral manipulation, and dry teat-directed behavior between calves fed acidified versus nonacidified milk replacer. In a study by Todd et al. (2016), milk replacer acidification tended to be associated with earlier solid feed consumption, where median time to onset of solid feed consumption for calves with free access to acidified versus nonacidified milk replacer was 32 and $39.5 \mathrm{~d}$, respectively. Thus, if calves in the current study had been observed longer, 
acidified-fed calves may have been observed redirecting their oral behavior toward solid feed once motor patterns for mastication were more fully developed.

Calves assigned to the restricted feeding treatments tended to show more nutritive teat-engaged behavior than the free-access calves. These results may initially seem counterintuitive; one would expect restricted feeding to be associated with less, not more, nutritive sucking activity (Jensen and Holm, 2003; Borderas et al., 2009a; Miller-Cushon et al., 2013). In the current study, however, the relationship between feeding level and nutritive teat-engaged behavior was confounded by nonnutritive sucking. To be specific, the nutritive teat-engaged behavior of the RA and RN calves included both nutritive sucking (sucking to obtain milk) and nonnutritive sucking events (sucking but no milk available), whereas the nutritive teat-engaged behavior of the FA and FN calves included only nutritive sucking events. This situation occurred because the feeding equipment setup (nutritive teats and feeding buckets separated by a solid wall) prevented observers from establishing when the restricted-fed calves finished their milk allotment. Calves fed restricted quantities of milk replacer, under management conditions similar to those of the current study, have been shown to engage in considerable nonnutritive sucking activity (De Paula Vieira et al., 2008; Miller-Cushon et al., 2013). Restricted milk feeding has been found to increase occupancy times in automated milk feeders because calves perform a large number of visits to the teat where they are not rewarded with milk (De Paula Vieira et al., 2008; Borderas et al., 2009a). In addition, de Passillé and Rushen (2006a) premilked cows and demonstrated that calves respond to reduced milk availability in the udder by spending more time nursing, having longer sucking duration, performing more frequent but shorter sucking bouts, and engaging in greater butting and teat switching behavior. Thus, based on the observed differences in nutritive teat-engaged behavior, one can infer that restricted-fed calves spent at least some time, perhaps a significant amount, sucking on the nutritive teat after their allotment of milk replacer had been consumed.

Restricted feeding tended to be associated with longer sucking bouts and greater total sucking bout duration, which is consistent with the results of earlier research that has examined the effects of feeding level on the feeding behavior of calves (Appleby et al., 2001; De Paula Vieira et al., 2008; Borderas et al., 2009a; Miller-Cushon et al., 2013). Calves with restricted milk allowances will typically consume their total milk allotment very quickly, often in a single nutritive sucking bout and without any pauses, followed by several short nonnutritive sucking bouts (De Paula Vieira et al., 2008; Miller-Cushon et al., 2013). In the current study, the tendency for restricted-fed calves to engage in longer sucking bouts over the free-access calves can be attributed to more frequent sucking and pausing behavior within bouts (de Passillé and Rushen, 2006a; Miller-Cushon et al., 2013). The within-bout sucking events for restricted-fed calves would have likely corresponded to both nutritive and nonnutritive sucking behavior. The within-bout pauses would have resulted from calves changing their feeding position, butting the nutritive teat, performing teat-seeking behavior, directing oral behavior toward the environment, moving to a new location in the pen, or simply requiring a short withdrawal from actively sucking milk. Feeding level did not affect the total number of sucking bouts performed daily, which suggests that social facilitation may have influenced the calves' feeding behavior. Solid pen partitions prevented visual contact between calves, but all calves were housed in a quiet barn and within auditory range of one another. Thus, calves may have used auditory cues, such as the sound of a neighboring calf rising, moving within its pen, and beginning to suck its teat, to stimulate the onset of sucking behavior. Auditory stimuli have been shown to affect the drinking and ingestive behavior of newly weaned piglets (Petrie and Gonyou, 1988).

Calves that are given access to a nutritive artificial teat and an unrestricted supply of milk have been shown to voluntarily consume milk at rates approximately twice that of calves reared using traditional feeding practices (Appleby et al., 2001; Jasper and Weary, 2002), and distribute their daily milk intake across several small, frequent meals in a diurnal feeding pattern (Hammell et al., 1988; Senn et al., 2000; Miller-Cushon et al., 2013). In contrast, traditionally fed calves usually receive their restricted daily allotments of milk as 2 large meals, and each meal is consumed rapidly, often in a single nutritive bout within minutes of milk delivery (Appleby et al., 2001; De Paula Vieira et al., 2008; Miller-Cushon et al., 2013). Therefore, given that restricted-fed calves exhibited greater nutritive teat-engaged behavior across a similar number of sucking bouts in comparison to free-access calves, at least some of their sucking behavior likely corresponded with nonnutritive sucking visits (de Passillé and Rushen, 2006a; Miller-Cushon et al., 2013). Restricted-fed calves routinely engage in periods of nonnutritive sucking immediately after consuming an allotment of milk, as well as at other times throughout the day, in an attempt to gain access to milk when it is unavailable (Jensen and Holm, 2003; De Paula Vieira et al., 2008; Borderas et al., 2009a). Nonnutritive sucking and unrewarded visits are recognized as behavioral signs of hunger in calves (De Paula Vieira et al., 2008; Roth et al., 2009; Rosenberger et al., 2017). Therefore, the tendency for restricted-fed calves to exhibit greater 
sucking bout duration, as well as perform more sucking and pausing behavior within sucking bouts, provides evidence that these calves were hungry and likely had a stronger motivation to obtain milk than calves reared under free-access feeding conditions. Alternatively, the longer and more fragmented sucking bouts by the restricted-fed calves may have been associated with feeding frustration, in response to no longer being able to gain access to milk replacer from the nutritive teat once the calf's allotment had been consumed. Thwarting of feeding behavior has been reported to induce a state of frustration, characterized by greater oral behavior directed toward the feeder, pen objects, and neighbors, more grooming, and increased activity or pacing, in other livestock species (Duncan and Wood-Gush, 1972; Carbonaro et al., 1992; Lewis, 1999). More research is needed to better understand the effects of hunger and frustration on the feeding behavior of calves reared on free-access versus restricted milk feeding levels.

The effects of acidification on lying behavior are largely unknown. It was our hypothesis that acidifiedfed calves would engage in more lying behavior because lower gastric $\mathrm{pH}$ may have caused gastrointestinal discomfort. Calves fed large amounts of milk have previously been shown to spend less time standing and more time lying down than restricted-fed calves (De Paula Vieira et al., 2008; Borderas et al., 2009a). Calves with free access to milk replacer were expected to spend a greater amount of time in a recumbent position over those calves on the restricted feeding treatments. Unexpectedly, results of this study demonstrated that acidification and feeding level did not affect lying time. Lack of differences in lying time in the current study may have been due to the young age of the calves, type of housing management system used, or low statistical power. de Passillé et al. (2016) documented that standing and lying behavior during the first week of life can vary widely between individual calves, with daily standing time ranging from 1.5 to $6.5 \mathrm{~h}$ (median $=4.4$ $\mathrm{h}$ ) and mean lying bout duration ranging from 14.6 to 92.8 min (median $=59.2 \mathrm{~min}$ ). Calves offered pasteurized whole milk at 30 versus $8 \%$ of BW did not differ for lying behavior from 1 to $3 \mathrm{~d}$ of age, spending an average of 20.5 and $20.0 \mathrm{~h} / \mathrm{d}$, respectively, lying down (Borderas et al., 2009b). These reports of lying behavior for calves in the first week of life are in line with the daily lying time observed in the current study. Differences in lying behavior for calves fed larger amounts of milk have been shown at older ages. Borderas et al. (2009a) reported that at 2 wk of age, calves offered ad libitum milk replacer had similar daily lying time to those fed $4 \mathrm{~L} / \mathrm{d}$; however, at 4 to 5 wk of age, calves fed $12 \mathrm{~L} / \mathrm{d}$ of whole milk spent significantly more time lying down than calves fed $4 \mathrm{~L} / \mathrm{d}$.
Much of the earlier research that examined the effects of feeding level on the lying behavior of calves was conducted using group-housed calves (De Paula Vieira et al., 2008; Borderas et al., 2009a). Lying behavior of group-housed calves would be influenced by several social factors, such as competition for lying space, social facilitation, and group composition. Thus, the individual housing system used in the current study, compared with the group housing system and the associated social interactions between calves in the previous reports, may have accounted in part for the lack of difference in the lying behavior of calves. Borderas et al. (2009b), however, reported similar daily lying times at 1 to $3 \mathrm{~d}$ of age for individually housed calves offered pasteurized whole milk at 30 or $8 \%$ of BW.

The primary limitation of this work was the sample size, with only 16 calves enrolled in the study. Tendencies were reported for several feeding behavior parameters between calves fed free access and restricted, as well as grooming behavior for calves consuming acidified versus nonacidified milk replacer. The lack of statistically significant differences $(P<0.05)$ between treatment groups could be attributed to this small sample size and the elevated risk of type II error.

\section{CONCLUSIONS}

Calves that consumed acidified milk replacer showed more fragmented feeding patterns, characterized by more pausing behavior within a sucking bout and longer sucking bout duration, than calves fed nonacidified milk replacer. Moreover, calves assigned to the acidified feeding treatments tended to perform more grooming behavior than calves fed nonacidified milk replacer. The observed differences in feeding and grooming behavior suggest that acidification may have reduced the palatability of milk replacer, although calves did not reject this feedstuff. Restricted-fed calves tended to have longer sucking bouts and performed more withinbout sucks and pauses than free-access calves. Overall, this research provides new information into how acidification of milk replacer affects the feeding behavior of calves fed different levels of milk; this information is beneficial for optimizing the palatability of different nutritional programs for young calves.

\section{ACKNOWLEDGMENTS}

Financial support for this study was provided by Natural Sciences and Engineering Research Council of Canada (Ottawa, ON, Canada), Ontario Ministry of Agriculture, Food and Rural Affairs (Guelph, ON, Canada), Dairy Farmers of Ontario (Mississauga, ON, Canada) and Ontario Veal Association (Guelph, ON, 
Canada). In-kind support for this was study was provided by Grober Nutrition (Cambridge, ON, Canada). The authors thank Danielle Cardinal, Leah Montgomery, Hauke Timm, and Albert Koekkoek of the University of Guelph (Kemptville, ON, Canada), as well as the staff and students of the Kemptville Campus Dairy Education and Innovation Center (Kemptville, ON, Canada) for technical support. William Sears (Department of Population Medicine, Guelph, ON, Canada) is acknowledged for his advice on statistical analyses.

\section{REFERENCES}

Appleby, M. C., D. M. Weary, and B. Chua. 2001. Performance and feeding behaviour of calves on ad libitum milk from artificial teats. Appl. Anim. Behav. Sci. 74:191-201. https://doi.org/10.1016/ S0168-1591(01)00171-X.

Argagón, Y. A. 2007. The Use of Acids to Preserve Feedstuffs. C. Lückstädt, ed. Nottingham University Press, Nottingham, UK.

Armengol, R., and L. Fraile. 2016. Colostrum and milk pasteurization improve health status and decrease mortality in neonatal calves receiving appropriate colostrum ingestion. J. Dairy Sci. 99:4718 4725. https://doi.org/10.3168/jds.2015-10728.

Borderas, T. F., A. M. B. de Passillé, and J. Rushen. 2009a. Feeding behavior of calves fed small or large amounts of milk. J. Dairy Sci. 92:2843-2852. https://doi.org/10.3168/jds.2008-1886.

Borderas, T. F., A. M. B. de Passillé, and J. Rushen. 2009b. Termperature preferences and feed level of the newborn dairy calf. Appl. Anim. Behav. Sci. 120:56-61. https://doi.org/10.1016/j.applanim .2009.04.010

Burghardt, G. M. 1967. The primacy effect of the first feeding experience in the snapping turtle. Psychon. Sci. 7:383-384. https://doi .org/10.3758/BF03331135.

Carbonaro, D. A., T. H. Friend, G. R. Dellmeier, and L. C. Nuti 1992. Behavioral and physiological responses of dairy goats to food thwarting. Physiol. Behav. 51:303-308. https://doi.org/10.1016/ 0031-9384(92)90145-R

CCAC (Canadian Council on Animal Care). 2009. CCAC Guidelines on the Care and Use of Farm Animals in Research, Teaching and Testing, Canadian Counc. Anim. Care, Ottawa, ON, Canada. https://www.ccac.ca/Documents/Standards/Guidelines/Farm _Animals.pdf.

Chua, B., E. Coenen, J. van Delen, and D. M. Weary. 2002. Effects of pair versus individual housing on the behavior and performance of dairy calves. J. Dairy Sci. 85:360-364. https://doi.org/10.3168/ JDS.S0022-0302(02)74082-4.

Collings, L. K. M., K. L. Proudfoot, and D. M. Veira. 2011. The effects of feeding untreated and formic acid-treated colostrum ad libitum on intake and immunoglobulin levels in dairy calves. Can. J. Anim. Sci. 91:55-59. https://doi.org/10.4141/CJAS10043.

Cummins, C., I. Lorenz, and E. Kennedy. 2016. Short communication: The effect of storage conditions over time on bovine colostral immunoglobulin G concentration, bacteria, and pH. J. Dairy Sci. 99:4857-4863. https://doi.org/10.3168/jds.2015-10276.

de Passillé, A. M., M. Rabeyrin, and J. Rushen. 2016. Associations between milk intake and activity in the first days of a calf's life and later growth and health. Appl. Anim. Behav. Sci. 175:2-7.

de Passillé, A. M., and J. Rushen. 2006a. Calves' behaviour during nursing is affected by feeding motivation and milk availability. Appl. Anim. Behav. Sci. 101:264-275.

de Passillé, A. M., and J. Rushen. 2006b. What components of milk stimulate sucking in calves? Appl. Anim. Behav. Sci. 101:243-252.

De Paula Vieira, A., V. Guesdon, A. M. de Passillé, M. A. G. von Keyserlingk, D. M. Weary, A. R. R. de la Fe, and P. Pradel. 2008. Behavioural indicators of hunger in dairy calves. Appl. Anim. Behav. Sci. 109:180-189. https://doi.org/10.1016/j.applanim.2007.03.006.
DeVries, T. J., M. A. G. von Keyserlingk, D. M. Weary, and K. A. Beauchemin. 2003. Measuring the feeding behavior of lactating dairy cows in early to peak lactation. J. Dairy Sci. 86:3354-3361.

Diaz, M. C., M. E. Van Amburgh, J. M. Smith, J. M. Kelsey, E. L. Hutten, and W. A. Verstegen. 2001. Composition of growth of Holstein calves fed milk replacer from birth to 105-kilogram body weight. J. Dairy Sci. 84:830-842. https://doi.org/10.3168/ jds.S0022-0302(01)74541-9.

Dohoo, I., W. Martin, and H. Stryhn. 2010. Veterinary Epidemiologic Research. VER Inc., Charlottetown, Prince Edward Island, Canada.

Drackley, J. K. 2008. Calf nutrition from birth to weaning. Vet. Clin. North Am. Food Anim. Pract. 24:55-86. https://doi.org/10.1016/ j.cvfa.2008.01.001.

Duncan, I. J. H., and D. G. M. Wood-Gush. 1972. Thwarting of feeding behaviour in the domestic fowl. Anim. Behav. 20:444-451. https://doi.org/10.1016/S0003-3472(72)80007-1.

Gelsinger, S. L., A. J. Heinrichs, and C. M. Jones. 2016. A metaanalysis of the effects of preweaned calf nutrition and growth on first-lactation performance. J. Dairy Sci. 99:6206-6214. https:// doi.org/10.3168/jds.2015-10744.

Goatcher, W. D., and D. C. Church. 1970. Taste responses in ruminants. 4. Reactions of pygmy goats, normal goats, sheep and cattle to acetic acid and quinine hydrochloride. J. Anim. Sci. 31:373-382.

Hammell, K. L., J. H. M. Metz, and P. Mekking. 1988. Sucking behaviour of dairy calves fed milk ad libitum by bucket or teat Appl. Anim. Behav. Sci. 20:275-285. https://doi.org/10.1016/0168 -1591(88)90052-4.

Hellekant, G. C. Hård af Segerstad, and T. W. Roberts. 1994. Sweet taste in the calf: III. Behavioral responses to sweeteners. Physiol. Behav. 56:555-562. https://doi.org/10.1016/0031-9384(94)90301 -8 .

Hellekant, G., T. Roberts, D. Elmer, T. Cragin, and V. Danilova. 2010. Responses of single chorda tympani taste fibers of the calf (Bos taurus). Chem. Senses 35:383-394. https://doi.org/10.1093/ chemse/bjq026.

Hill, T. M., H. G. Bateman, J. M. Aldrich, J. D. Quigley, and R. L. Schlotterbeck. 2013. Evaluation of ad libitum acidified milk replacer programs for dairy calves. J. Dairy Sci. 96:3153-3162. https:// doi.org/10.3168/jds.2012-6132.

Jamaluddin, A. A., T. E. Carpenter, D. W. Hird, and M. C. Thurmond. 1996a. Economics of feeding pasteurized colostrum and pasteurized waste milk to dairy calves. J. Am. Vet. Med. Assoc. 209:751-756.

Jamaluddin, A. A., D. W. Hird, M. C. Thurmond, and T. E. Carpenter. 1996b. Effect of preweaning feeding of pasteurized and nonpasteurized milk on postweaning weight gain of heifer calves on a Californian dairy. Prev. Vet. Med. 28:91-99. https://doi.org/ 10.1016/0167-5877(96)01040-9.

Jasper, J., and D. M. Weary. 2002. Effects of ad libitum milk intake on dairy calves. J. Dairy Sci. 85:3054-3058. https://doi.org/10.3168/ jds.S0022-0302(02)74391-9.

Jensen, M. B. 2009. Short communication: Milk meal pattern of dairy calves is affected by computer-controlled milk feeder set-up. J. Dairy Sci. 92:2906-2910.

Jensen, M. B., and L. Holm. 2003. The effect of milk flow rate and milk allowance on feeding related behaviour in dairy calves fed by computer controlled milk feeders. Appl. Anim. Behav. Sci. 82:87100. https://doi.org/10.1016/S0168-1591(03)00054-6.

Khan, M. A., H. J. Lee, W. S. Lee, H. S. Kim, K. S. Ki, T. Y. Hur, G. H. Suh, S. J. Kang, and Y. J. Choi. 2007a. Structural growth, rumen development, and metabolic and immune responses of Holstein male calves fed milk through step-down and conventional methods. J. Dairy Sci. 90:3376-3387. https://doi.org/10.3168/jds 2007-0104.

Khan, M. A., H. J. Lee, W. S. Lee, H. S. Kim, S. B. Kim, K. S. Ki, J. K. Ha, H. G. Lee, and Y. J. Choi. 2007b. Pre- and postweaning performance of Holstein female calves fed milk through step-down and conventional methods. J. Dairy Sci. 90:876-885. https://doi .org/10.3168/jds.S0022-0302(07)71571-0. 
Khan, M. A., D. M. Weary, and M. A. G. von Keyserlingk. 2011. Invited review: Effects of milk ration on solid feed intake, weaning, and performance in dairy heifers. J. Dairy Sci. 94:1071-1081. https://doi.org/10.3168/jds.2010-3733.

Lewis, N. 1999. Frustration of goal-directed behaviour in swine. Appl. Anim. Behav. Sci. 64:19-29. https://doi.org/10.1016/S0168 $-1591(99) 00025-8$.

Macdonald, P. D. M., and P. E. J. Green. 1988. User's Guide to Program MIX: An Interactive Program for Fitting Mixtures of Distributions. Release 2.3, January 1988. Ichthus Data Systems, Hamilton, Ontario, Canada.

Martin, P. R., and P. P. G. Bateson. 1993. Measuring Behaviour: An Introductory Guide. 2nd ed. Cambridge University Press, Cambridge, UK.

Miller-Cushon, E. K., R. Bergeron, K. E. Leslie, and T. J. DeVries. 2013. Effect of milk feeding level on development of feeding behavior in dairy calves. J. Dairy Sci. 96:551-564. https://doi.org/10 $.3168 /$ jds.2012-5937.

Mills, D. S., and C. A. Macleod. 2002. The response of crib-biting and windsucking in horses to dietary supplementation with an antacid mixture. Ippologia 13:33-41.

Nicol, C. J., and A. J. Badnell-Waters. 2005. Suckling behaviour in domestic foals and the development of abnormal oral behaviour. Anim. Behav. 70:21-29. https://doi.org/10.1016/j.anbehav.2004 .10 .012 .

Nicol, C. J., H. P. D. Davidson, P. A. Harris, A. J. Waters, and A. D. Wilson. 2002. Study of crib-biting and gastric inflammation and ulceration in young horses. Vet. Rec. 151:658-662.

Parker, A. M., J. K. House, M. S. Hazelton, K. L. Bosward, V. L. Mohler, F. P. Maunsell, and P. A. Sheehy. 2016. Milk acidification to control the growth of Mycoplasma bovis and Salmonella Dublin in contaminated milk. J. Dairy Sci. 99:9875-9884. https://doi.org/ 10.3168/jds.2016-11537.

Petrie, C. L., and H. W. Gonyou. 1988. Effects of auditory, visual and chemical stimuli on the ingestive behavior of newly weaned piglets. J. Anim. Sci. 66:661-668. https://doi.org/10.2527/jas1988 $.663661 \mathrm{x}$.

Provenza, F. D., and D. F. Balph. 1987. Diet learning by domestic ruminants: Theory, evidence and practical implications. Appl. Anim. Behav. Sci. 18:211-232. https://doi.org/10.1016/0168 -1591(87)90218-8.

Rosenberger, K., J. Costa, H. Neave, M. von Keyserlingk, and D. Weary. 2017. The effect of milk allowance on behavior and weight gains in dairy calves. J. Dairy Sci. 100:504-512. https://doi.org/10 $.3168 /$ jds.2016-11195.

Roth, B. A., N. M. Keil, L. Gygax, and E. Hillmann. 2009. Temporal distribution of sucking behaviour in dairy calves and influence of energy balance. Appl. Anim. Behav. Sci. 119:137-142. https://doi org/10.1016/j.applanim.2009.03.006.

Senn, M., S. Gross-Lüem, H. Leuenberger, and W. Langhans. 2000. Meal patterns and meal-induced metabolic changes in calves fed milk ad lib. Physiol. Behav. 70:189-195.

Soberon, F., E. Raffrenato, R. W. Everett, and M. E. Van Amburgh. 2012. Preweaning milk replacer intake and effects on long-term productivity of dairy calves. J. Dairy Sci. 95:783-793. https://doi .org/10.3168/jds.2011-4391.

Soberon, F., and M. E. Van Amburgh. 2013. Lactation Biology Symposium: The effect of nutrient intake from milk or milk replacer of preweaned dairy calves on lactation milk yield as adults: A meta-analysis of current data. J. Anim. Sci. 91:706-712. https:// doi.org/10.2527/jas.2012-5834.

Stewart, S., S. Godden, R. Bey, P. Rapnicki, J. Fetrow, R. Farnsworth, M. Scanlon, Y. Arnold, L. Clow, K. Mueller, and C. Ferrouillet. 2005. Preventing bacterial contamination and proliferation during the harvest, storage, and feeding of fresh bovine colostrum. J. Dairy Sci. 88:2571-2578. https://doi.org/10.3168/jds.S0022 $-0302(05) 72933-7$.

Sutherland, M. A., G. M. Worth, C. Cameron, C. M. Ross, and D. Rapp. 2017. Health, physiology, and behavior of dairy calves reared on 4 different substrates. J. Dairy Sci. 100:2148-2156. https://doi .org/10.3168/jds.2016-12074.

Todd, C. G., K. E. Leslie, S. T. Millman, J. M. Sargeant, H. Migdal, K. Shore, N. G. Anderson, and T. J. DeVries. 2016. Milk replacer acidification for free-access feeding: Effects on the performance and health of veal calves. Open J. Anim. Sci. 6:234-246. https:// doi.org/10.4236/ojas.2016.63029.

Veissier, I., P. Chazal, P. Pradel, and P. Le Neindre. 1997. Providing social contacts and objects for nibbling moderates reactivity and oral behaviors in veal calves. J. Anim. Sci. 75:356-365. https://doi .org $/ 10.2527 / 1997.752356 \mathrm{x}$

Villalba, J. J., F. Catanese, F. D. Provenza, and R. A. Distel. 2012. Relationships between early experience to dietary diversity, acceptance of novel flavors, and open field behavior in sheep. Physiol. Behav. 105:181-187. https://doi.org/10.1016/j.physbeh.2011.08 031.

Willard, J. G., J. C. Willard, S. A. Wolfram, and J. P. Baker. 1977. Effect of diet on cecal $\mathrm{pH}$ and feeding behavior of horses. J. Anim. Sci. 45:87-93.

Woodford, S. T., H. D. Whetstone, M. R. Murphy, and C. L. Davis. 1987. Abomasal pH, nutrient digestibility, and growth of Holstein bull calves fed acidified milk replacer. J. Dairy Sci. 70:888-891. https://doi.org/10.3168/jds.S0022-0302(87)80088-7. 